\title{
What's in Your Yogurt? A Proteomic Investigation
}

Rose C Gooding", Johnathan Yeaton\#, Frances Wallace", Erin McTarnaghan\#, Armand G Ngounou Wetie, Izabela Sokolowska and Costel C Darie* $^{*}$

Department of Chemistry \& Biomolecular Science, Biochemistry \& Proteomics Group, Clarkson University, USA

\#These authors contributed equally

\begin{abstract}
Different kinds of yogurt contain different percentages of proteins. However, do they also contain different types of proteins? To answer to this question, we investigated the protein pattern in the soluble fraction of various yogurts. We found that many yogurts contain mostly two main bands: a $\sim 20 \mathrm{kDa}$ band and a $\sim 15 \mathrm{kDa}$ band. Proteomics analysis of these two bands led us to conclude that the $20 \mathrm{kDa}$ band corresponds to lactoglobulin isoforms and the $15 \mathrm{kDa}$ band corresponds to casein isoforms.
\end{abstract}

Keywords: Mass spectrometry; Proteomics; Proteins

\section{Introduction}

Different kinds of yogurt possess different percentages of protein. According to their label, most varieties of Greek yogurts contain between $18 \mathrm{~g}$ and $14 \mathrm{~g}$ of protein, which is about $34 \%$ of an adults daily intake. Chobani, a widely known brand of Greek yogurt, states that there are 5 active cultures in their yogurt, and that their straining process is the reason behind the high protein concentration. Low fat yogurt, such as the brand Lite and Fit, is another example of a Greek yogurt, but the manufacturer claims to have a lower percentage of proteins, containing a mere $5 \mathrm{~g}$ per serving. With less active cultures and fortified with mostly artificial sweeteners, most low fat yogurts lack natural benefits that would allow for a higher protein concentration. Another example of a variety of Greek yogurt with a low protein concentration is organic yogurt. Free of artificial flavoring and bioengineered products, Stonyfield organic yogurt contains 6 grams of proteins per serving. There are also yogurts marketed to aid in digestion. Activia, which differs from its other Greek yogurt counterparts due to the fact that it is high in fiber and manufacturers claim that Activa only contains about $5 \mathrm{~g}$ of proteins per serving. Soybeans byproducts can also be used to create yogurt as a non-dairy alternative. Yogurt containing soybean products are lower in protein than their milk containing counterparts due to a process that strips soybeans of their essential nutrients. All these servings indicate the amount of protein per serving and the percent of daily protein intake, but having different volumes per serving, one must also be aware about the serving size. While it is known that all these yogurts contain proteins and these proteins are either soy or milk proteins, it is not known what specific proteins are
A
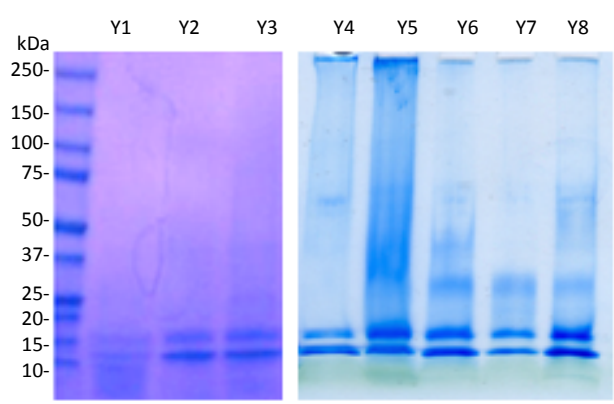

Figure 1: Coomassie-stained SDS-PAGE gels of various types of yogurts Note that samples $Y 1-Y 3(A)$ and samples $Y 4-Y 8(B)$ were analyzed by two different teams, at two years interval $(2012$ (A) and 2010 (B). the most abundant in yogurts, specifically in the soluble part of the yogurts. Here we employed a proteomic approach in an undergraduate Biochemistry \& Biotechnology Laboratory to investigate the protein composition within different types of yogurts and to identify the most important protein components. Proteomics uses mass spectrometry as the main tool to investigate the protein component in a sample [1-9]. Our results suggest that the soluble fractions of the yogurts contain a very small number of proteins, most of them identified as caseins and lactoglobulins, both milk proteins.

\section{Materials}

Equal volumes of different yogurts $\left(6 \mathrm{~cm}^{3}\right)$ were intensely vortexed and then centrifuged at $14,000 \mathrm{rpm}$ for 10 minutes at $4^{\circ} \mathrm{C}$ three times. The supernatant was then buffer exchanged and then transferred to labeled, capped test tubes, and then stored in refrigerator at $4^{\circ} \mathrm{C}$. Each yogurt supernatant was then separated by SDS-PAGE according to published procedures [10-13]. The gels were then stained with Coomassie blue, and the most intense bands were excised and digested with trypsin. Digested proteins were then analyzed by nanoliquid chromatography tandem mass spectrometry (nano LC-MS/MS) using a Nano Acquity UPLC coupled to a QTOF Micro mass spectrometer, according to published procedures [13-19]. The raw data were processed using Protein Lynx Global Server (PLGS, version 2.4) and the resulting pkl files were submitted to Mascot database search [13-19].

\section{Results and Discussion}

We investigated the most abundant, soluble proteins in a variety of yogurts. Surprisingly, we did not see to many soluble proteins in these yogurts. An SDS-PAGE that shows the protein pattern of these various yogurts is shown in Figure 1. As observed, two main bands can be observed in the SDS-PAGE of these yogurts: a $\sim 20 \mathrm{kDa}$ band and a $\sim 13 \mathrm{kDa}$ band (yogurt samples Y1-Y8). It should be noted that the samples Y1-Y3 (Figure 1A) and samples Y4-Y8 (Figure 1B) were

*Corresponding author: Costel C Darie, Department of Chemistry \& Biomolecular Science, Biochemistry \& Proteomics Group, Clarkson University, 8 Clarkson Avenue, Potsdam, NY, 13699-5810, USA, Tel: 315-268-7763; Fax: 315-268-6610; E-mail: cdarie@clarkson.edu

Received January 30, 2014; Accepted February 28, 2014; Published March 04, 2014

Citation: Gooding RC, Yeaton J, Wallace F, McTarnaghan E, Wetie AGN, et al (2014) What's in Your Yogurt? A Proteomic Investigation. Mod Chem appl 2: 121 doi:10.4172/2329-6798.1000121

Copyright: (c) 2014 Gooding RC, et al. This is an open-access article distributed under the terms of the Creative Commons Attribution License, which permits unrestricted use, distribution, and reproduction in any medium, provided the original author and source are credited. 
Citation: Gooding RC, Yeaton J, Wallace F, McTarnaghan E, Wetie AGN, et al. (2014) What's in Your Yogurt? A Proteomic Investigation. Mod Chem appl 2: 121. doi:10.4172/2329-6798.1000121

analyzed by two different teams at two years interval (samples Y1-3 were analyzed in 2012, while samples Y4-Y8 were analyzed in 2010). Occasionally, a $34 \mathrm{kDa}$ band could also be observed (Figure 1B, Y6Y8). To reveal the identity of these proteins, proteomics was employed using the two gel bands, which were excised, digested with trypsin and analyzed using nanoLC-MS/MS. A database search revealed two types of proteins: lactoglobulins (alpha and beta lactoglobulins) and caseins (alpha-S1 and kappa caseins). The molecular mass of lactoglobulins is consistent with the $\sim 20 \mathrm{kDa}$ protein band, while the molecular mass of the caseins is consistent with the $\sim 14 \mathrm{kDa}$ band. The Total Ion Chromatogram (TIC) and the mass (MS) and tandem mass (MS/MS) spectra whose analysis led to identification of a peptide that is part of Beta-lactoglobulin are shown in Figure 2. The MS/MS spectra whose analysis led to identification of peptides that were part of Alphalactoglobulin and Alpha-S1-Casein are shown in Figure 3.

\section{Conclusion}

In conclusion, we interrogated the soluble fraction of the yogurts by SDS-PAGE to determine the protein pattern and the main protein bands that were observed in the Coomassie-stained SDS-PAGE gels were further analyzed by nanoLC-MS/MS. The results are consistent with the mass of the proteins identified by nanoLC-MS/MS (lactoglobulins and caseins) and with milk as the source of the proteins in yogurts.

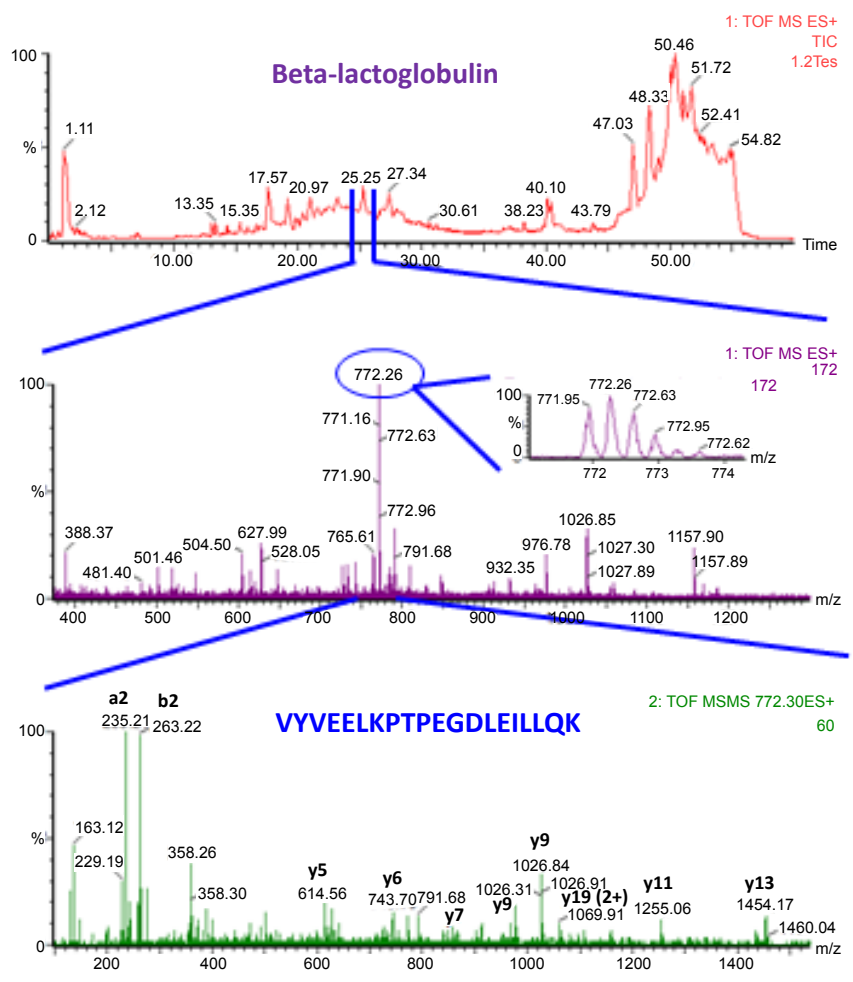

Figure 2: NanoLC-MS/MS analysis of the $20 \mathrm{kDa}$ band observed in the SDSPAGE shown in Figure 1. In the total ion chromatogram (TIC, top), at minute 25 , a series of multiply charged ions eluted and were recorded by the mass spectrometer as TOF-MS, shown in the middle panel. Here a triply charged peak (circled and also shown in the inbox) with mass-to-charge ratio $(\mathrm{m} / \mathrm{z})$ of 771.95 was selected for fragmentation by MS/MS, shown in the lower panel. The fragmentation of this peak produced a series of peaks that correspond to a series of $a, b$ and $y$ ions, whose analysis led to identification of a peptide with the amino acid sequence VYVEELKPTPEGDLEILLQK, which is part of Beta-lactoglobulin.
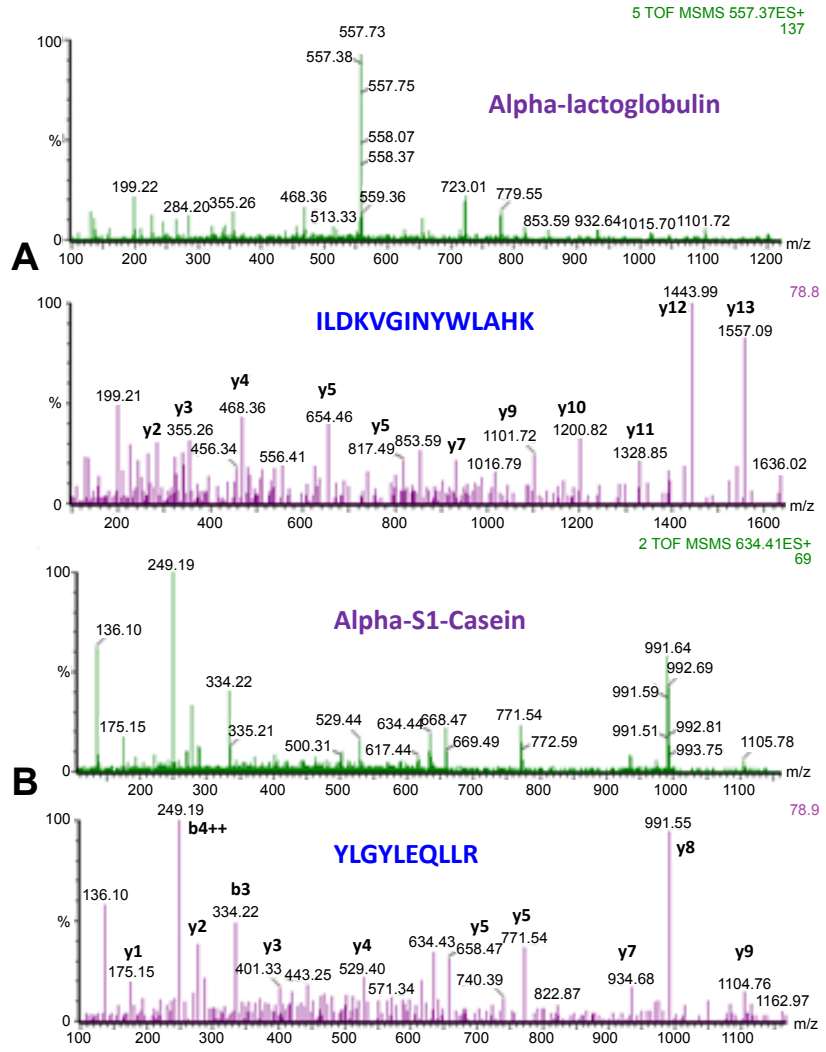

Figure 3: MS/MS spectra of peptide mixtures that were part of the $20 \mathrm{kDa}$ band $(A)$ and $14 \mathrm{kDa}$ band $(B)$ in the SDS-PAGE gels shown in Figure 1. Data analysis of these MS/MS spectra led to identification of peptides with the amino acid sequences ILDKVGINYWLAHK (A) and YLGYLEQLLR (B) which were part of Alpha-lactoglobulin (A) and Alpha-S1-Casein, respectively. In A the top MS/MS psectrum is unprocessed spectrum and the bottom spectrum is the deconvoluted spectrum shown in the top. Deconvolution processes the multiply charged peaks into singly charged peaks, for an easier data analysis. For example, the peak in the top with $\mathrm{m} / \mathrm{z}$ of 723.01 is double charged and upon deconvolution, it becomes a singly charged peak with $\mathrm{m} / \mathrm{z}$ of 1443.99 in the spectrum from the bottom. The same explanation applied to the spectra shown in (B).

\section{Acknowledgement}

This work was in part supported by the Department of Chemistry \& Biomolecular Science and by the Biochemistry \& Proteomics Group at Clarkson University and by the current chairman of the department, Dr. Phillip Christiansen We thank Dr. Alisa Woods for comments on the manuscript.

\section{References}

1. Aebersold R, Mann M (2003) Mass spectrometry-based proteomics. Nature 422: 198-207.

2. Blagoev B, Kratchmarova I, Ong SE, Nielsen M, Foster LJ, et al. (2003) A proteomics strategy to elucidate functional protein-protein interactions applied to EGF signaling. Nat Biotechnol 21: 315-318.

3. Darie CC, Shetty V, Spellman DS, Zhang G, Xu C, et al. (2008) Blue Native PAGE and mass spectrometry analysis of the ephrin stimulation- dependent protein-protein interactions in NG108-EphB2 cells. Applications of Mass Spectrometry in Life Safety, NATO Science for Peace and Security Series A: Chemistry and Biology 3-22.

4. Gygi SP, Rist B, Gerber SA, Turecek F, Gelb MH, et al. (1999) Quantitative analysis of complex protein mixtures using isotope-coded affinity tags. Nat Biotechnol 17: 994-999.

5. Alastair Aitken (2005) Identification of post-translational modifications by mass spectrometry. The Proteomics Protocols Handbook 431-437. 
Citation: Gooding RC, Yeaton J, Wallace F, McTarnaghan E, Wetie AGN, et al. (2014) What's in Your Yogurt? A Proteomic Investigation. Mod Chem appl 2: 121. doi:10.4172/2329-6798.1000121

Page 3 of 3

6. Ong SE, Foster LJ, Mann M (2003) Mass spectrometric-based approaches in quantitative proteomics. Methods 29: 124-130.

7. Han X, Aslanian A, Yates JR $3^{\text {rd }}(2008)$ Mass spectrometry for proteomics. Curr Opin Chem Biol 12: 483-490.

8. Thome J, Coogan AN, Woods AG, Darie CC, Habler F (2011) CLOCK Genes and Circadian Rhythmicity in Alzheimer Disease. J Aging Res 2011: 383091.

9. Zhang G, Ueberheide BM, Waldemarson S, Myung S, Molloy K, et al. (2010) Protein quantitation using mass spectrometry. Methods Mol Biol 673: 211-222.

10. Darie CC, De Pascalis L, Mutschler B, Haehnel W (2006) Studies of the Ndh complex and photosystem II from mesophyll and bundle sheath chloroplasts of the C4-type plant Zea mays. J Plant Physiol 163: 800-808.

11. Darie CC, Litscher ES, Wassarman PM (2008) Structure, processing, and polymerization of rainbow trout egg vitelline envelope proteins. Applications of Mass Spectrometry in Life Safety, NATO Science for Peace and Security Series A: Chemistry and Biology, 23-36.

12. Sokolowska I, Gawinowicz MA, Ngounou Wetie AG, Darie CC (2012) Disulfide proteomics for identification of extracellular or secreted proteins. Electrophoresis 33: 2527-2536.

13. Sokolowska I, Ngounou Wetie AG, Roy U, Woods AG, Darie CC (2013) Mass spectrometry investigation of glycosylation on the NXS/T sites in recombinan glycoproteins. Biochim Biophys Acta 1834: 1474-1483.
14. Ngounou Wetie AG, Sokolowska I, Woods AG, Wormwood KL, Dao S, et al. (2013) Automated mass spectrometry-based functional assay for the routine analysis of the secretome. J Lab Autom 18: 19-29.

15. Petrareanu C, Macovei A, Sokolowska I, Woods AG, Lazar C, et al. (2013) Comparative proteomics reveals novel components at the plasma membrane of differentiated HepaRG cells and different distribution in hepatocyte- and biliary-like cells. PLoS One 8: e71859.

16. Roy U, Sokolowska I, Woods AG, Darie CC (2012) Structural investigation of tumor differentiation factor. Biotechnol Appl Biochem 59: 445-450.

17. Sokolowska I, Dorobantu C, Woods AG, Macovei A, Branza-Nichita N, et al. (2012) Proteomic analysis of plasma membranes isolated from undifferentiated and differentiated Hepa RG cells. Proteome Sci 10: 47.

18. Sokolowska I, Woods AG, Gawinowicz MA, Roy U, Darie CC (2012) Identification of a potential tumor differentiation factor receptor candidate in prostate cancer cells. FEBS J 279: 2579-2594.

19. Woods AG, Sokolowska I, Darie CC (2012) Identification of consistent alkylation of cysteine-less peptides in a proteomics experiment. Biochem Biophys Res Commun 419: 305-308. 